\title{
Sonophotocatalytic degradation of poly (vinyl pyrrolidone) in the presence of $\mathrm{Fe}(\mathrm{III}) / \mathrm{H}_{2} \mathrm{O}_{2}$
}

\author{
N. S. Orang*, R. Abdollahi \\ Department of Chemical Engineering, Islamic Azad University-Ahar Branch, Ahar, Iran
}

Email address:

n-sadeghpour@iau-ahar.ac.ir (N. S. Orang)

To cite this article:

N. S. Orang, R. Abdollahi. Sonophotocatalytic Degradation of Poly (Vinyl Pyrrolidone) in the Presence of Fe (III)/ $\mathrm{H}_{2} \mathrm{O}_{2}$. American Journal of Physical Chemistry. Vol. 3, No. 3, 2014, pp. 26-32. doi: 10.11648/j.ajpc.20140303.11

\begin{abstract}
The degradation of poly (vinyl pyrrolidone) (PVP) by means of ultrasound irradiation and its combination with homogeneous photocatalysis (photo-Fenton) was investigated. Emphasis was given on the effect of additive on degradation rate constants. $24 \mathrm{kHz}$ of ultrasound irradiation was provided by a sonicator, while an ultraviolet source of 16 $\mathrm{W}$ was used for UV irradiation. To increase the efficiency of degradation process, degradation system was combined with Fe (III) $\left(2.5 \times 10^{-4} \mathrm{~mol} / \mathrm{L}\right)$ and $\mathrm{H}_{2} \mathrm{O}_{2}(0.020-0.118 \mathrm{~mol} / \mathrm{L})$ in the presence of UV irradiation and the rate of degradation process change from $4.07 \times 10^{-5}$ to $8.24 \times 10^{-5} \mathrm{~mol}^{1.5} \cdot l^{-1.5} \cdot \mathrm{min}^{-1}$. Photo-Fenton process led to complete PVP degradation in 150 min with the rate increasing with increasing catalyst loading. Sonophotocatalysis in the presence of $\mathrm{Fe}(\mathrm{III}) / \mathrm{H}_{2} \mathrm{O}_{2}$ was always faster than the respective individual processes. A negative order for the dependence of the reaction rate on total molar concentration of PVP solution within the degradation process was suggested. Results of this study indicate that the presence of catalyst in the reaction medium can be utilized to reduce molecular weight of PVP while maintaining the power of irradiated ultrasound.
\end{abstract}

Keywords: Poly (Vinyl Pyrrolidone), Sono-Fenton, Sonophoto-Fenton, $\mathrm{Fe}(\mathrm{III}) / \mathrm{H}_{2} \mathrm{O}_{2}$, Viscosity

\section{Introduction}

Early work in understanding the response of polymeric materials to mechanical stress was published by Staudinger, who observed a decrease in the molecular weight of polymers in response to mastication. It was suggested that the molecular weight reduction resulted from homolytic carbon-carbon bond cleavage due to mechanical force [1]. Mechanical stress can be in the form of ultrasound waves and the related process is named ultrasonic degradation. Ultrasound can be used to apply force to dilute polymer solutions. Since its initial use to degrade starch and agar [2], this technique has also been employed to degrade cellulose [3], polypeptides, polysaccharides [4, 5], proteins [6], DNA [7], transition metal-coordinated polymers [8-10], and various organic polymers $[11,12]$.

Depending on the application, polymers and gels may need to be degraded to reduce their molecular weight through the shortening of the polymeric chains that can be achieved by various methods. Different methods of degradation are available such as thermal, photo and catalytic degradation $[13,14]$. Beside the ultrasonic degradation method, the methods like photocatalysis [15] and microwave [16] are also important. Polymers can be degraded thermally by pyrolysis or in solution. But the process is energy intensive. Therefore, alternative energy reducing techniques required for degradation process are important. Ultrasound, photo and chemical methods are less energy-intensive polymer degradation. Further, the mechanism by which they interact with the polymeric systems can help get insight into the degradation pathways or mechanisms [17].

Polymer chain scission results from solvodynamic shear caused by cavitation: the nucleation, growth, and collapse of bubbles in solution. A polymer molecule near the vicinity of a collapsing bubble is pulled toward the cavity of the bubble, and the solvodynamic shear elongates the polymer backbone, leading to scission [18]. Scission generally occurs near the midpoint of a polymer chain (approximately within the middle $15 \%$ of the chain, in the case of homopolymer), where solvodynamic forces are the greatest [19]. The rate of cleavage from ultrasonic irradiation of polymer solutions depends on several experimental factors, including temperature, solvent, and sonication intensity [20]. The ultrasonic energy is dissipated in solution, resulting in cavitations. Cavitation 
produces vibrational wave energy, shear stresses at the cavitation interphase, and local high pressure and temperature. These are the major factors causing the degradation of polymers [21-23].

Practically, cavitation can be produced at a considerably lower applied acoustic pressure due to the presence of weak spots in the liquid. Weak spots include the presence of gas nuclei in the form of dissolved gases, minute suspended gas bubbles, or tiny suspended particles. When produced in a sound field at sufficiently high power, the formation of cavitation bubbles will be initiated during the rarefaction cycle [24]. Cavitation may cause enhanced polymerization or depolymerization reactions by temporarily dispersing aggregates or by permanently breaking chemical bonds in polymeric chains [25]. Recently, $\mathrm{H}_{2} \mathrm{O}_{2}$ has been used in the degradation of some polysaccharides because it is easily available an environmentally benign [26-29]. R. Ebrahimi et al. was worked on Photo-Assisted Sonodegradation of Hydrogels in the Presence of TiO2 nanoparticles. They was found that mechanical effect of ultrasonic irradiation was rupture the gel network and decrease the viscosity of gel system [30].

Moreover, the simultaneous use of ultrasound and photocatalysis, so-called sonophotocatalysis has been studied regarding process efficiency to degrade various organics. Although photocatalysis and sonolysis have been extensively employed individually for the degradation applications, their combined use (sonophotocatalysis) has received appreciably less attention. In the present study, we investigated the degradation of PVP by the sono-Fenton and sonophoto-Fenton treatments in the presence of different values of $\mathrm{H}_{2} \mathrm{O}_{2}$ concentrations. The effect of combination of ultrasound with UV irradiation and Fe (III) addition was explored with a particular focus on the rate of degradation reaction. Particular attention was paid to the synergistic effect existing between hybrid processes of ultrasonic and photocatalytic oxidation.

\section{Experimental}

\subsection{Materials}

Polyvinyl pyrrolidone (PVP) with weight-average molecular weight $1300000 \mathrm{kDa}$ was purchased from Across Co. Ltd. Hydrogen peroxide and $\mathrm{Fe}\left(\mathrm{NO}_{3}\right)_{3} \cdot 9 \mathrm{H}_{2} \mathrm{O}$ used in Fenton-like experiments, as well as all other chemicals were of laboratory reagent grade and were purchased from Merck. All solutions were prepared using distilled and deionized water.

\subsection{Methods}

\subsubsection{PVP Solution Preparation}

PVP solutions containing 5g/L PVP were prepared. The solutions were stirred overnight to ensure complete solubilisation of the PVP molecules, and then filtered to remove any impurities and $100 \mathrm{ml}$ samples were immediately sonicated.

\subsubsection{Experimental Setup and Procedure}

Reactions were carried out in a cylindrical $100 \mathrm{ml}$ Pyrex glass vessel. An ultrasound generator (Dr. Hielscher Ultrasonic Processor UP200 H) operating at a fix frequency of $24 \mathrm{kHz}$ and a variable power output up to $100 \mathrm{~W}$ nominal value, in aqueous media was used for sonication experiments. A titanium probe immersed in liquid from the open to the atmosphere top of the vessel was used to deliver the ultrasound energy in the reaction mixture. The bottom of the vessel was fitted with a glass cylindrical tube housing the light source; there were a pair of $8 \mathrm{~W}$ UV lamp, which emitted in the 200-300 nm wavelength range with a maximum at $254 \mathrm{~nm}$. The vessel was fed with a $100 \mathrm{ml}$ PVP solution and the reaction temperature in the case of sonolysis, sonocatalysis and sonophotocatalysis was kept constant at $25 \pm 1^{\circ} \mathrm{C}$ through the use of cooling water circulating through the double-walled compartment, thus acting as cooling jacket. The reaction vessel was covered with a dark cloth to avoid unwanted photochemical reactions induced by natural light.

Different treatments were tested, namely: Fe (III) $/ \mathrm{H}_{2} \mathrm{O}_{2}$ assisted sonolysis (US+Fenton), $\mathrm{Fe}$ (III) $/ \mathrm{H}_{2} \mathrm{O}_{2}$-assisted photocatalysis (UV+Fenton) and Fenton-assisted combined sonolysis and photocatalysis (US+UV+Fenton). Quite often, for the experiments being done in the presence of Fe (III), $\mathrm{H}_{2} \mathrm{O}_{2}$ was used as an extra oxidant. While its concentration was varying in the range of $0.0195-0.118 \mathrm{~mol} / \mathrm{L}$, the concentration of $\mathrm{Fe}$ (III) was selected at a fix value of $2.5 \times 10^{-4} \mathrm{~mol} / \mathrm{L}$. These Fenton reagents for $0.0195,0.0392$, $0.0588,0.0784,0.0974$ and $0.118 \mathrm{~mol} / \mathrm{L}$ of $\mathrm{H}_{2} \mathrm{O}_{2}$ nominated as Fenton 1, 2, 3, 4, 5 and 6, respectively.

\subsection{Viscosity Measurements}

The intrinsic viscosities of the original PVP and its degraded solutions at $25^{\circ} \mathrm{C}$ were measured using the capillary viscometer (Setavic Kinematic viscometer). The internal capillary diameter was $0.05 \mathrm{~mm}$. Efflux times were measured for PVP solutions $\left(t_{s}\right)$ and the solvent $\left(t_{0}\right)$. Measurement of efflux times were repeated two times and average efflux time was then converted to the ratio of $t_{s} / t_{0}$, which is proportional to relative viscosity, $\eta_{\mathrm{r}}$, of PVP solution.

$$
\begin{gathered}
\eta_{r}=\frac{t_{s}}{t_{0}} \\
\eta_{s p}=\eta_{r}-1
\end{gathered}
$$

The intrinsic viscosity $[\eta]$ values can be related to the specific viscosity, $\eta_{\mathrm{sp}}$, and relative viscosity, $\eta_{\mathrm{r}}$, by the Huggins and Kramer equations [31]. The conditions used in this work $\left(\alpha=0.55\right.$ and $\left.\mathrm{k}=6.67 \times 10^{-5} \mathrm{lg}^{-1}\right)$ were adopted on the basis of previous findings in the literature [32, 33].

\subsection{Kinetic Model}

The rate of degradation is defined as the number of 
scission that occurs in $1 \mathrm{~L}$ in unit time and we must keep in mind that a scission in a chain yields two pieces. Thus, the rate equation of the degradation is as follows [34]:

$$
R=\frac{d[M]}{d t}=k M^{n}
$$

Where, $\mathrm{M}$, is the total molar concentration of the polymer, $k$, is the rate constant and, $\mathrm{n}$, is the order of reaction with respect to the total molar concentration of the polymer. From the experimental data, it is clear that the degradation rate decreases with increasing solution concentration, so " $n$ " is negative. It is noted that solution concentration $(\mathrm{g} / \mathrm{L})$ is constant and the total molar concentration $(\mathrm{mol} / \mathrm{L})$ increases during the degradation of polymer. The solution of differential Eq. (3) is:

$$
M^{1-n}-M_{0}^{1-n}=(1-n) k t
$$

Where $\mathrm{M}_{0}$ is the initial total molar concentration of polymer. The total molar concentration is related to the number average molecular weight through [35]

$$
M=\frac{C}{M_{n}}
$$

Moreover, viscosity average molecular weight, $M_{v}$, is related to the number average molecular weight, $M_{n}$, through [36].

$$
M_{v}=[(1+\alpha) \Gamma(1+\alpha)]^{\frac{1}{\alpha}} M_{n}
$$

Where, $\Gamma(1+\alpha)=\int_{0}^{\infty} e^{-t} t^{\alpha} d t, \mathrm{M}_{\mathrm{v}}$ is related to the intrinsic viscosity, $[\eta]$, through Marck-Houwink equation:

$$
M_{v}=\left(\frac{[\eta]}{\mathrm{k}}\right)^{\frac{1}{\alpha}}
$$

Where $\alpha$ and $\mathrm{k}$ are the Mark-Houwink constants.

Finally, $[\eta]$ can be related to the specific viscosity, $\eta_{\mathrm{sp}}$, and relative viscosity, $\eta_{\mathrm{r}}$, by Huggins and Kramer equations [31]:

$$
\begin{array}{r}
\frac{\eta_{s p}}{C}=[\eta]+\mathrm{k}[\eta]^{2} C \\
\frac{L n \eta_{r}}{C}=[\eta]+(\mathrm{k}-0.5)[\eta]^{2} C
\end{array}
$$

From Eq. (8) and (9), intrinsic viscosity is:

$$
[\eta]=\frac{\left[2\left(\eta_{s p}-L n \eta_{r}\right)\right]^{0.5}}{C}
$$

Substitution of Eq. (10) in (6) and Eq. (7) in (6) yields

$$
M_{n}=\left(\frac{\left[2\left(\eta_{s p}-L n \eta_{r}\right)\right]^{0.5}}{C \mathrm{k}[(1+\alpha) \Gamma(1+\alpha)]}\right)^{\frac{1}{\alpha}}
$$

Finally, the substitution Eq. (11) in (5) yields:

$$
M=\left(\frac{C^{\alpha+1} \mathrm{k}[(1+\alpha) \Gamma(1+\alpha)]}{\sqrt{2}}\right)^{\frac{1}{\alpha}} \Delta \eta
$$

In addition, substitution Eq. (12) in (4) yields:

$$
\Delta \eta^{1-n}-\Delta \eta_{0}^{1-n}=(1-n)\left(\frac{\sqrt{2}}{C^{\alpha+1} \mathrm{k}[(1+\alpha) \Gamma(1+\alpha)]}\right)^{\frac{1-n}{\alpha}} k t
$$

or

$$
\Delta \eta^{1-n}-\Delta \eta_{0}^{1-n}=k^{\prime} t
$$

\section{Results and Discussion}

\subsection{Determination of Reaction Order of Degradation of $\boldsymbol{P V P}$}

A number of different rate models have been proposed for the degradation of polymers $[37,38]$, but in this study a simple model was employed via viscometry. Using Eq. 12, in the initial sonication, for different concentration of polymer we calculate total molar concentration of polymer. The results are depicted in Fig. 1.

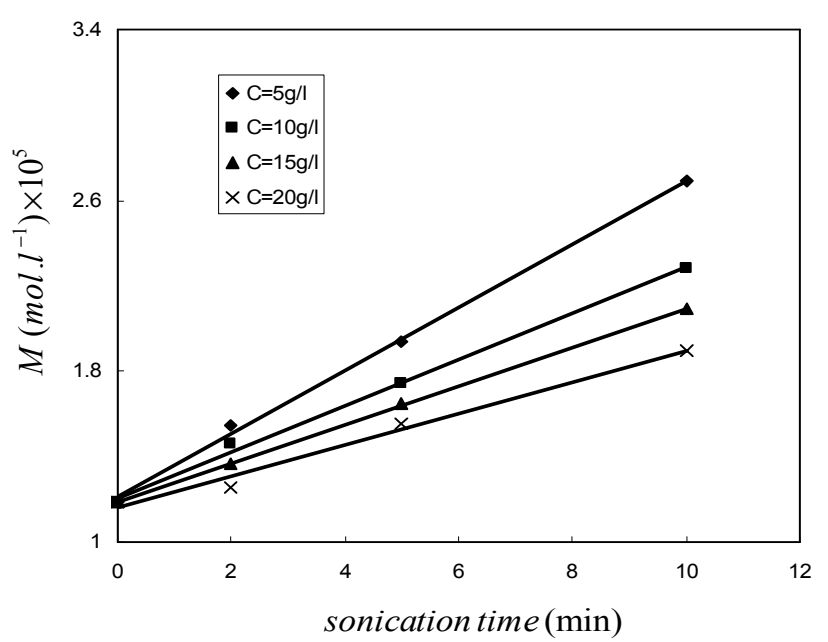

Fig 1. Variation of total molar concentration with sonication time for different concentration of PVP solutions at $25^{\circ} \mathrm{C}$.

The slopes of plots give the initial rate of degradation sing Eq.3, the plot of Log R versus Log [M] are linear and it is shown in Fig. 2.The slope of curve is -0.5 , which suggest the order of reactions with respect to total molar concentration of polymer $[39,40]$.

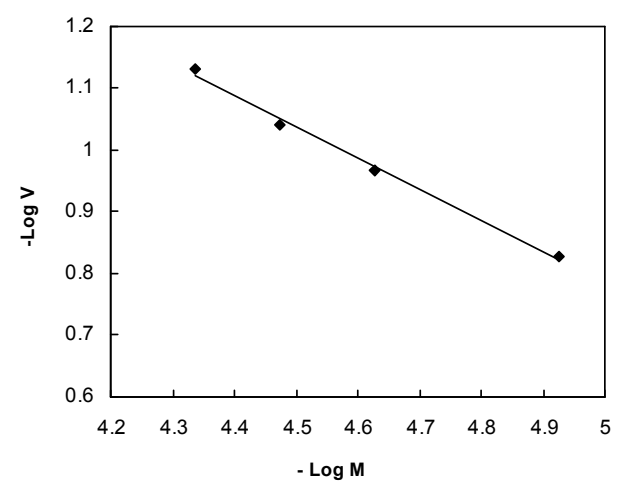

Fig 2. The plot of lnR versus lnM for degraded $P V P$ at $25^{\circ} \mathrm{C}$. 
From substitution of the value of " $n$ " in Eq.14, we obtain the following:

$$
\Delta \eta^{1.5}-\Delta \eta_{0}^{1.5}=k^{\prime} t
$$

\subsection{PVP Degradation by Sono-Fenton Process}

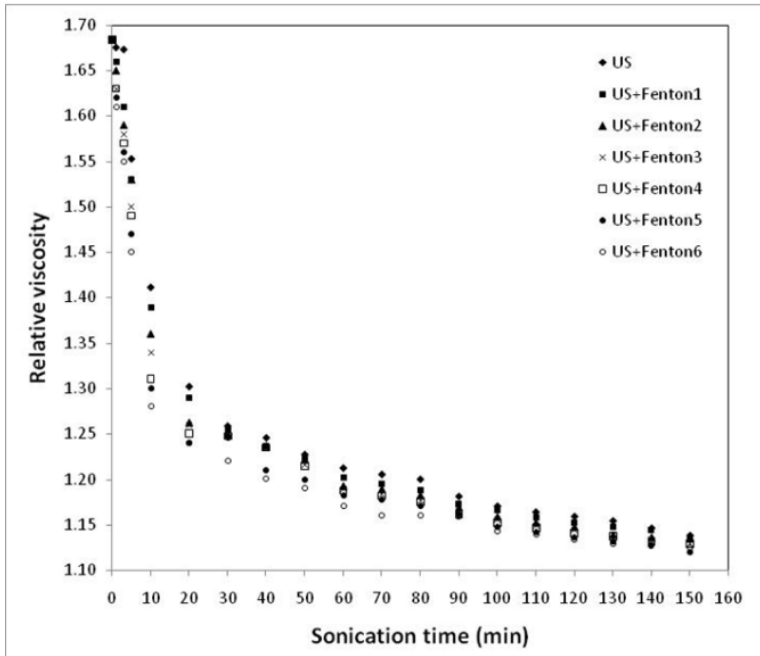

Fig 3. The relationship between $\eta_{r}$ and sonication time in sono-Fenton process, for different Fenton reagents.

Using of ultrasound power method with increasing power, without any additives has an increasing effect in degradation process rate constant. For example when the power of ultrasound increased from 30 to $90 \mathrm{~W}$, the rate constant increased from 3.64 to $7.92 \times 10^{-5}\left(\mathrm{~mol}^{1.5} \cdot \mathrm{L}^{-1.5} \cdot \mathrm{min}^{-1}\right)$. Nevertheless, the addition of Fenton reagents in a fix power of ultrasound $(30 \mathrm{~W})$ can be a versatile factor to maintain the reaction rate in the cited range. Fig. 3 shows the effect of increasing of $\mathrm{H}_{2} \mathrm{O}_{2}$ content on relative viscosity $\left(\eta_{\mathrm{r}}\right)$ of PVP solution as a function of the sonication time at $5 \mathrm{~g} / \mathrm{L}$ initial PVP concentration, constant power of ultrasound $(30 \mathrm{~W})$ and $\mathrm{Fe}(\mathrm{III})$ ions concentration $\left(2.5 \times 10^{-4} \mathrm{~mol} / \mathrm{L}\right)$. The reason of using an constant concentration of Fe (III) ions is that an increase in Fe(III) loadings could play a role in the excessive formation of $\mathrm{Fe}(\mathrm{II})$, which can compete with the organic carbon and scavenge hydroxyl radicals, whose concentration is expected to be low due to the relatively low sonolytically produced $\mathrm{H}_{2} \mathrm{O}_{2}$ concentration [41]. As seen, $\eta_{\mathrm{r}}$ decreases with increasing the content of $\mathrm{H}_{2} \mathrm{O}_{2}$ from $0.2 \mathrm{ml}$ to $1.2 \mathrm{ml}$. The plots of $\Delta \eta^{1.5}-\Delta \eta_{0}^{1.5}$ versus sonication time for different content of Fenton are presented in Fig.4. The apparent degradation rate constant, $k^{\prime}$,defined in Eq. 15, can be estimated from the slopes of the plots in Fig.4. Based on these results, degradation rate constants, $k$, were calculated that are shown in Table 1 . It can be seen that at the same power of ultrasound, the extent of degradation increases with an increase in applied $\mathrm{H}_{2} \mathrm{O}_{2}$ value of Fenton reagent. In principle, $\mathrm{Fe}$ (III) $/ \mathrm{H}_{2} \mathrm{O}_{2}$ system may enhance degradation providing additional nuclei for bubble formation. These results are shown in Table 1.These data indicated that when metal ions in the reaction system increased, the reaction rate increased. This proved that metal ions were essential to the degradation process. Metal ions might form complexes with amino group of PVP and hydroxyl radicals formed by $\mathrm{H}_{2} \mathrm{O}_{2} / \mathrm{Fe}$ (III) could inducedegradation of PVP.

Table 1. Initial PVP degradation rate constants in the various degradation conditions at $5 \mathrm{~g} / \mathrm{L}$ concentration and $25^{\circ} \mathrm{C}$.

\begin{tabular}{ccc}
\hline Process & $\begin{array}{c}\mathbf{H}_{\mathbf{2}} \mathbf{O}_{\mathbf{2}} \mathbf{c o n t e n t} \\
(\mathbf{m l})\end{array}$ & $\begin{array}{c}\boldsymbol{k} \times \mathbf{1 0} \mathbf{5}^{\mathbf{1}} \\
\left(\mathbf{m o l}^{\mathbf{1 . 5}} \mathbf{.} \mathbf{L}^{\mathbf{- 1 . 5}} \cdot \mathbf{m i n}^{-\mathbf{1}}\right)\end{array}$ \\
\hline US & 0.00 & 4.073 \\
US & 0.20 & 4.357 \\
US & 0.40 & 4.602 \\
US & 0.60 & 5.034 \\
US & 0.80 & 5.339 \\
US & 1.00 & 5.741 \\
US & 1.20 & 6.087 \\
UV & 0.20 & 0.034 \\
UV & 0.40 & 0.065 \\
UV & 0.60 & 0.101 \\
UV & 0.80 & 0.135 \\
UV & 1.00 & 0.197 \\
UV & 1.20 & 0.206 \\
US+UV & 0.00 & 1.234 \\
US+UV & 0.20 & 4.574 \\
US+UV & 0.40 & 5.128 \\
US+UV & 0.60 & 5.983 \\
US+UV & 0.80 & 6.400 \\
US+UV & 1.00 & 7.083 \\
US+UV & 1.20 & 8.246 \\
\hline & &
\end{tabular}

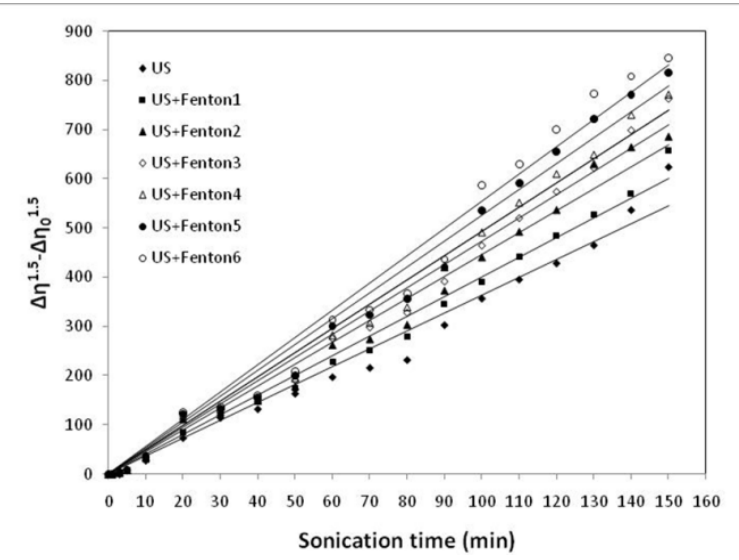

Fig 4. The plot of $\Delta \eta^{1.5}-\Delta \eta_{0}^{1.5}$ versus the sonication time in sonoFenton process, for different Fenton reagents at $25^{\circ} \mathrm{C}$.

\subsection{PVP Degradation by Sonophoto-Fenton Process}

Sonophotocatalytic process result in $\mathrm{OH}^{*}$ radical generation in Fenton [41] and Fenton-like reactions (reactions 16-20) [42]( The efficiency of the photo-Fenton system is closely related to iron participating in the following redox cycle generating two hydroxyl radicals per molecules of $\mathrm{H}_{2} \mathrm{O}_{2}$ decomposed:

$$
\begin{gathered}
\mathrm{Fe}^{2+}+\mathrm{H}_{2} \mathrm{O}_{2} \rightarrow \mathrm{Fe}^{3+}+\mathrm{OH}^{\bullet}+\mathrm{OH}^{-} \\
\mathrm{Fe}^{3+}+\mathrm{H}_{2} \mathrm{O}+\mathrm{h} v(\lambda<450 \mathrm{~nm}) \rightarrow \mathrm{Fe}^{2+}+\mathrm{OH}^{\bullet}+\mathrm{H}^{+} \\
\mathrm{Fe}^{3+}+\mathrm{H}_{2} \mathrm{O}_{2}=\mathrm{Fe}^{2+}-\mathrm{OOH}+\mathrm{H}^{+}
\end{gathered}
$$




$$
\begin{gathered}
\mathrm{Fe}^{2+}-\mathrm{OOH} \rightarrow \mathrm{Fe}^{2+}+\mathrm{HOO}^{\bullet} \\
\mathrm{Fe}^{3+}+\mathrm{HOO}^{\bullet} \rightarrow \mathrm{Fe}^{2+}+\mathrm{O}_{2}+\mathrm{H}^{+}
\end{gathered}
$$

In where hydrogen peroxide is produced by ultrasonic irradiation. The acceleration for degradation of PVP would be in accordance with the photolysis of iron aquacomplex, $\mathrm{Fe}(\mathrm{OH})^{2+}$ providing a new source of $\mathrm{OH}^{\circ}$ radicals. $[43,44]$.

$$
\mathrm{Fe}(\mathrm{OH})^{2+}+h v \rightarrow \mathrm{Fe}^{2+}+\mathrm{OH}^{\bullet}
$$

The Fe (II) regenerated reacts with $\mathrm{H}_{2} \mathrm{O}_{2}$. Therefore, the combination would exhibit considerable enhancement in the degradation of PVP. Fig. 5 shows relative viscositysonication time curves during the sonophotocatalytic degradation of PVP at an initial concentration of $5 \mathrm{~g} / \mathrm{L}$ and various $\mathrm{H}_{2} \mathrm{O}_{2}$ values, and plots of the $\Delta \eta^{1.5}-\Delta \eta_{0}^{1.5}$ versus

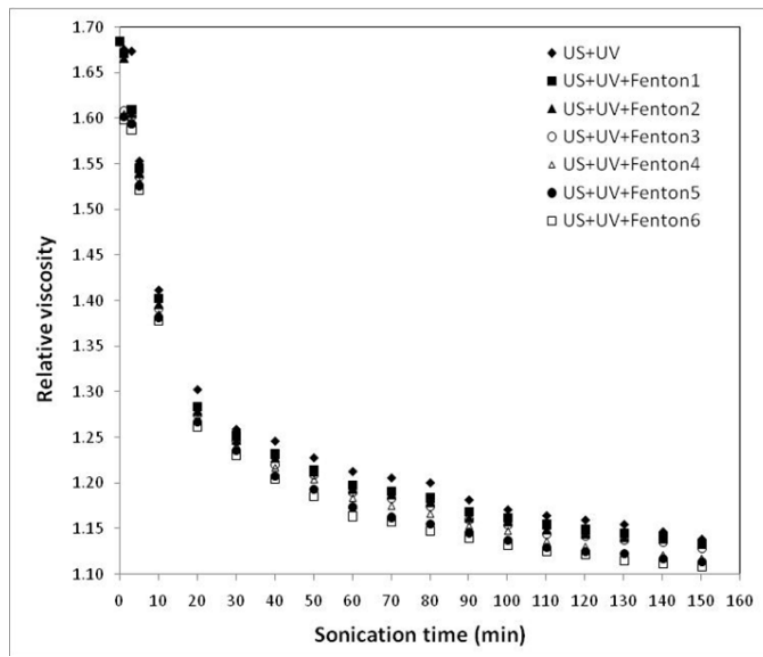

Fig 5. The relationship between $\eta_{r}$ and sonication time in sonophotoFenton process, for different Fenton reagents at constant power of ultrasound $(30 \mathrm{~W})$ at $25^{\circ} \mathrm{C}$.

Sonication times are presented in Fig. 6, while values of degradation rate constants are summarized in Table 1 . As clearly seen, sonophotocatalytic degradation occurs appreciably faster than sonocatalytic and photocatalytic degradation under similar experimental conditions. For instance, in the case of sonocatalytic and photocatalytic degradation in $150 \mathrm{~min}$ and at $0.2-1.2 \mathrm{~mL} \mathrm{H}_{2} \mathrm{O}_{2}$ values, rate constant is changed in the range of 4.357-6.087 and $0.034-0.206 \quad\left(\mathrm{~mol}^{1.5} \cdot \mathrm{L}^{-1.5} \cdot \mathrm{min}^{-1} \times 10^{5}\right)$, respectively.
While in the case of sonophotocatalytic degradation rate constant changed in the range of 4.574-8.246 $\left(\mathrm{mol}^{1.5} \cdot \mathrm{L}^{-1.5} \cdot \mathrm{min}^{-1} \times 10^{5}\right)$.

In order to investigate whether the synergistic effect is operative in the degradation of PVP treated with ultrasound and ultraviolet in the presence of $\mathrm{Fe}$ (III) $/ \mathrm{H}_{2} \mathrm{O}_{2}$, the individual photocatalytic degradation process was carried out in the conditions of $16 \mathrm{~W}$ and $60 \mathrm{~min}$. In the case of photo-Fenton degradation, the rate constant of reaction does not show a considerable change and the value of rate constant was very low in comparison by sono-Fenton or sonophoto-Fenton processes (Table 1).

Table 2. Rate constants corresponding to the sono-Fenton, photo-Fenton

\begin{tabular}{|c|c|c|c|c|}
\hline \multirow[b]{2}{*}{ Fenton Reagent } & \multicolumn{3}{|c|}{$\mathrm{k} \times 10^{5}\left(\mathrm{~mol}^{1.5} \cdot \mathrm{l}^{-1.5} \cdot \mathrm{min}^{-1}\right)$} & \multirow[b]{2}{*}{ \%synergy } \\
\hline & $\mathbf{k}_{\mathbf{U S}+\mathrm{UV}+\mathrm{Fenton}}$ & $\mathbf{k}_{\mathbf{U S}+F e n t o n}$ & $\mathbf{k}_{\mathbf{U V}+\text { Fenton }}$ & \\
\hline Fenton 1 & 4.574 & 4.357 & 0.034 & 4 \\
\hline Fenton 2 & 5.128 & 4.602 & 0.065 & 9 \\
\hline Fenton 3 & 5.983 & 5.034 & 0.101 & 14 \\
\hline Fenton 4 & 6.400 & 5.339 & 0.135 & 14 \\
\hline Fenton 5 & 7.083 & 5.741 & 0.197 & 16 \\
\hline Fenton 6 & 8.246 & 6.087 & 0.206 & 24 \\
\hline
\end{tabular}
and sonophoto-Fenton degradation and \%synergy between ultrasound and ultraviolet irradiation, at $5 \mathrm{~g} / \mathrm{L}$ concentration and $25^{\circ} \mathrm{C}$.

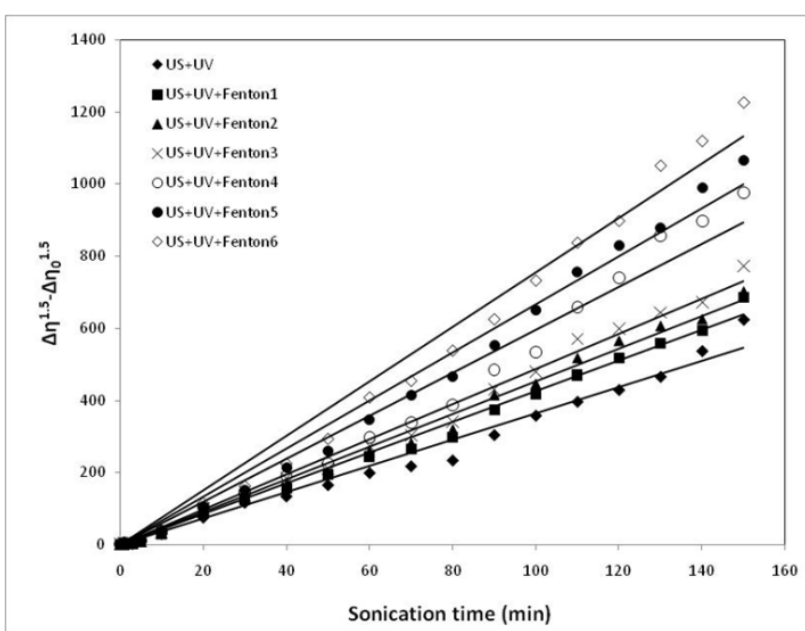

Fig 6. The plot of $\Delta \eta^{1.5}-\Delta \eta_{0}^{1.5}$ versus the sonication time in sonophotoFenton process, for different Fenton reagents at constant power of ultrasound $(30 \mathrm{~W})$ at $25^{\circ} \mathrm{C}$.

$$
\% \text { synegy }=100 \times \frac{k_{U S+U V+F e n t o n}-\left(k_{U S+F e n t o n}+k_{U V+F e n t o n}\right)}{k_{U S+U V+F e n t o n}}
$$

The reaction rate constants for applied degradation methods (sono-Fenton, photo-Fenton and sonophotoFenton) are summarized in Table 2. As seen from Table 1 and 2, sonophotocatalytic degradation generally occurs faster than that during the respective individual processes at similar operating conditions. Interestingly, there appears to be a synergistic effect between ultrasound and ultraviolet irradiation in the presence of Fenton system since rate constants of the combined process $\left(k_{U S+U V+F e n t o n}\right)$ are greater than the sum of the rate constants of the individual processes $\left(k_{U S+F e n t o n}+k_{U V+F e n t o n}\right)$. The synergy can be 
quantified as the normalized difference between the rate constants obtained under sonophotocatalysis and the sum of those obtained under separate photocatalysis and sonocatalysis [45].

\section{Conclusions}

Degradation of PVP in aqueous solution was investigated by sono-Fenton and sonophoto-Fenton processes. The degradation efficiency was affected by the value of Fenton reagent and the presence of ultraviolet irradiation as a secondary source of power to degradation. PVP achieved complete degradation under ultrasonic irradiation $(100 \mathrm{~W}$, $24 \mathrm{kHz}$ ) within $150 \mathrm{~min}$. Furthermore, the presence of $\mathrm{Fe}$ (III) under UV irradiation played a significant role in the efficiency of the sonochemical effect. The enhanced degradation of PVP was achieved by the increase in the oxidation power by the addition of Fe (III) under UV irradiation during sonication. The advantages of ultrasound/Fe (III)/UV system as an oxidative treatment are rapid degradation and simple handling.

\section{Acknowledgements}

We are grateful to the Vice-Dean of Research of Islamic Azad University-Ahar branch and it is necessary to notice that this article is extracted from a report of research work entitled "Sonolytic, sonocatalytic, photocatalytic and sonophotocatalytic degradation of poly (vinyl-pyrrolidone) (PVP) in the presence of $\mathrm{TiO}_{2}$ nanoparticles and $\mathrm{Fe}$ (III) $/ \mathrm{H}_{2} \mathrm{O}_{2}$ systems".

\section{References}

[1] W. Kauzmann, H. Eyring, The Viscous Flow of Large Molecules, J. Am. Chem. Soc. 62 (1940) 3113-3125.

[2] E. W. Flosdorf, L. A. Chambers, The chemical action of audible sound, J. Am. Chem. Soc. 55 (1933) 3051-3052.

[3] T. Sato, Effect of turnover rate on the change of concentration of an unstable compound in a dip coating bath, J. Coat. Technol. 72 (2000) 81-83.

[4] R. Czechowska-Biskupa, B. Rokita, S. Lotfy, P. Ulanski, J. M. Rosiak, Degradation of chitosan and starch by $360-\mathrm{kHz}$ ultrasound, Cabohydr. Polym. 60 (2005) 175-184.

[5] J. P. Lorimer, T. J. Mason, T. C. Cuthbert, E. A. Brookfield, Effect of ultrasound on the degradation of aqueous native dextran. Ultrason. Sonochem., 2 (1995) 555-557.

[6] J. H. Bradbury, J. O'Shea, The effect of ultrasonic irradiation on proteins, J. Aust. J. Biol. Sci. 26 (1973) 583-590.

[7] D. Freifelder, P. F. Davison, Studies on the sonic degradation of deoxyribonucleic acid, Biophys. J. 2 (1962) 235-247.

[8] J. M. J. Paulusse, R. P. Sijbesma, Reversible mechanochemistry of a Pd (II) coordination polymer, Angew. Chem. Int. Ed. 43 (2004) 4460-4462.
[9] S. Karthikeyan, S. L. Potisek, A. Piermattei, R. P. Sijbesma, Highly efficient mechanochemical scission of silver-carbene coordination polymers, J. Am. Chem. Soc. 130 (2008) 14968-14969.

[10] J. M. J. Paulusse, R. P. Sijbesma, Selectivity of mechanochemical chain scission in mixed palladium(II) and platinum(II) coordination polymers, Chem. Commun. 37 (2008) 4416-4418.

[11] Price, G. J. In Advances in Sonochemistry; Mason, T. J., Ed.; JAI: Cambridge, 1990; Vol. 1.

[12] K. S. Suslick, G. Price, Application of ultrasound to materials chemistry, J. Annu. Rev. Mater. Sci. 29 (1999) 295-326.

[13] H. H. G. Jellinek, Degradation of vinyl polymers. New York: Academic Press, 1955.

[14] G. J. Price, The use of ultrasound for the controlled degradation of polymer solutions. Advances in Sonochem. Jai Press, 1990.

[15] X. Li, Y. Cui, Ultraviolet-Induced Decomposition of Acrylic Acid-Based Superabsorbent Hydrogels Crosslinked with N, N-Methylenebisacrylamide, Appl. Polym. Sci. 108 (2008) 3435-3441.

[16] S. Caddick, Microwave Assisted Organic Reactions, Tetrahedron 51 (1995) 10403-10432

[17] Y. Li, J. Li, S. Guo, H. Li, Mechanochemical degradation kinetics of high-density polyethylene melt and its mechanism in the presence of ultrasonic irradiation, Ultrason. Sonochem. 12 (2005) 183-189.

[18] A.M. Basedow, K.H. Ebert, Ultrasonic degradation of polymers in solution, Adv.Polym. Sci. 22 (1977) 83-148.

[19] S. P. Vijayalakshmi, G. Madras, Effect of initial molecular weight and solvents on the ultrasonic degradation of poly(ethylene oxide), Polym. Degrad. Stab. 90 (2005) 116-122.

[20] N. Daraboina, G. Madras, Kinetics of the ultrasonic degradation of poly (alkyl methacrylates), Ultrason. Sonochem. 16 (2009) 273-279.

[21] A. Gronroons, P. Pirkonen, J. Heikkinen, J. Ihalainen, H. Mursunen, H. Sekki, Ultrasonic depolymerisation of aqueous polyvinyl alcohol, Ultrason. Sonochem. 8 (2001) 259-264.

[22] M. T. Taghizadeh, T. Asadpour, Effect of molecular weight on the ultrasonic degradation of poly (vinyl pyrrolidone), Ultrason. Sonochem. 16 (2009) 280-286.

[23] M. T. Taghizadeh, A. Bahadori, 2009, Degradation kinetics of poly(vinyl- pyrrolidone) under ultrasonic irradiation, J. Polym. Res. 16 (2009) 545-554.

[24] S. E. Shim, S. Ghose, A. Isayev, Polymer 43 (2002) 5535.

[25] I. Masselin, X. Chasseray, L. Durand-Bourlier, J. Laine, P. Syzaret, D. Lemordant, J. Membr. Sci. 181 (2001) 213.

[26] S. Tanioka, Y. Matsui, T. Irie, T. Takahiko, T. Tanigawa, Y. Tanaka, H. Shibata, K. Y. Sawa, Biosci. Biotech. Biochem. 60 (1996) 2001.

[27] C. Q. Qin, L. Xiao, Y. M. Du, M. Feng,X. W. Shi, J. Wuhan Univ. 46 (2000) 195.

[28] C. Q. Qin, Y. M. Du, L. Xiao, Polym. Degrad. Stab. 76 (2002) 211. 
[29] Y. Lu, G. Wei, J. Peng, Chinese J. Polym. Sci. 22 (2004) 439.

[30] R. Ebrahimi, G. Tarhandeh, S. Rafiey, M. Narjabadi, and H. Khani, J. of Korean Chem. Soc. 56 (2012) 92.

[31] D.W. van Krevelen, Properties of Polymers, third ed. (Elsevier, Amsterdam, 1990).

[32] R. H. Chen, Int. J. Biol. Macromol. 23 (1998) 135.

[33] W. Wang, B. Shuqin, S. Li, W. Qin, Int. J. Biol. Macromol. 13 (1991) 281.

[34] M.T. Taghizadeh, A. Mehrdad, Ultrason. Sonochem. 10 (2003) 309.

[35] M.P. Stovens, Polymer Chemistry. (Oxford University Press, New York, 1990).

[36] P. J. Flory, F. S. Leutner, J. Polym. Sci. 3 (1948) 880.

[37] G. Madras, S. Chattopadhyay, Polym. Degrad. Stab. 71 (2001) 273.
[38] T.G. Nguyen, H.H. Kausch, Adv. Polym. Sci. 100 (1992) 173.

[39] M.T. Taghizadeh, T. Asadpour, Ultrason. Sonochem. 16 (2009) 280.

[40] M. T. Taghizadeh, A. Bahadori, J. Polym. Res. 16 (2009) 545.

[41] M. Rodriguez, V. Sarria, S. Esplugas, C. Pulgarin, J. Photochem. Photobiol. A: Chem. 151 (2002) 129.]

[42] A. Safarzadeh-Amiri, J. R. Bolton, S. R. Cater, J. Adv. Oxid. Technol. 1 (1996) 18.

[43] N. Brand, G. Mailhot, M. Bolte, Environ. Sci. Technol. 32 (1998) 2715.

[44] H. Katsumata, S. Kaneco, T. Suzuki, K. Ohta, Y. Yobiko, Chemosphere 69 (2007) 1261.

[45] M. Mrowetz, C. Pirola, E. Selli, Ultrason. Sonochem. $10(2003) 247$. 